\title{
New steroids
}

$\mathrm{C}$ ORTICOSTEROIDS ARE USEFUL ANTI-INFLAMMATORY AGENTS acting at multiple sites of inflammatory activity. Corticosteroids inhibit the accumulation of leukocytes at sites of inflammation by reducing chemotactic activity and inducing peptide inhibition of membrane phospholipase A2, leading to reduced production of prostaglandins, leukotrienes and platelet activating factor. Corticosteroids suppress inflammatory mediator production inhibiting macrophage interleukin- 1 and tumour necrosis factor, and they inhibit leukocyte endothelial adhesion. ' Oral steroids (cortisone, prednisolone, triamcinolone and betamethasone) have been in use since the early '50s. Recently, new steroids have been developed for local use in topical applications in the skin and in aerosol formulations for treating asthma. These drugs include betamethasone, beclomethasone, budesonide and fluticasone. More recently, several formulations of new steroids have been adapted for use in inflammatory bowel disease (IBD). These drugs include tixocortal pivolate, budesonide and fluticasone.

Tixocortal pivolate is available in enema form only for treatment of left-sided ulcerative colitis (UC). ${ }^{2}$ Efficacy is similar to other topical corticosteroid preparations; however, the major disadvantage is the excessive cost. This is a major limiting factor which might limit use, particularly when there appears to be no therapeutic advantage from this medication.

Budesonide is available in topical enema preparations, and recently has been developed in a capsule formulation designed to release budesonide in the distal small bowel (budesonide, controlled ileal release). ${ }^{3}$ Budesonide shows much more affinity than comparable glucocorticoids in terms of relative potency to inhibit rat edema and relative affinity for rat glucocorticoid receptor. Budesonide has a structure similar to prednisolone and undergoes oxidative biotrans. formation in the liver $90 \%$ on the first-pass ( $10 \%$ oral bioavailability). ${ }^{4}$ This pharmacological property should allow an effective dose for anti-inflammatory action, with less systemic side effects than, eg, hydrocortisone and prednisone. Budesonide has a water solubility 100 times greater than that of fluticasone, which makes it likely to be a favoured preparation. Budesonide has been shown to be effective in treating patients with distal ulcerative proctitis, ${ }^{5,6}$ with the same efficacy of other forms of hydrocortisone. ${ }^{7}$ It is likely to be used mainly for patients with distal proctitis resistant to corticosteroids or aminosalicylic acid preparations depending on availability and cost. ${ }^{8}$

Budesonide, developed in a slow-release form for treating patients with Crohn's disease (CD), has been favourably assessed in open studies, ${ }^{9-11}$ and has recently been reported in two double-blind studies. 12,13

In Canada, a double-blind, randomized trial has been completed this year in 255 patients with active CD defined as a CD activity index (CDAI) of 200 or more, who received placebo or oral budesonide in doses ranging from 3 to $15 \mathrm{mg}$ daily for eight weeks. ${ }^{12}$ Patients had disease limited to the ileum with or without colonic disease to the hepatic flexure, verified by endoscopy and/or radiology. Efficacy was measured as a change in CDAI to 150 or less (clinical remission). The results showed that $9 \mathrm{mg}$ is the smallest effective dose, and that $15 \mathrm{mg}$ is not better than $9 \mathrm{mg}$ in inducing remission. Glucocorticoid side effects were not a major problem.

In Europe, a double-blind, 10-week trial comparing the safety and efficacy of $9 \mathrm{mg} /$ day oral budesonide versus $40 \mathrm{mg} /$ day prednisolone

Gastroenterology in the $90 \mathrm{~s}$ is a series of short articles addressing topical, controversial issues in the treatment of gastrointestinal disorders. The series is made possible through an educational grant from Astra Pharma Inc was performed in 176 patients with active CD. ${ }^{13}$ After eight weeks, budesonide was tapered to $6 \mathrm{mg}$. Tapering of prednisone started after two weeks, and continued gradually down to $5 \mathrm{mg}$ during the last week. Eighty-eight patients were allocated to each of the groups. At 10 weeks, remission (CDAI less than 50 ) was achieved in $53 \%$ of the patients treated with budesonide compared with $66 \%$ in the prednisolone group. The CDAI decreased significantly in both groups, but comparison between the groups showed no significant difference. Glucocorticoid-associated side effects were significantly less common in the budesonide group than the prednisolone group (12 patients versus 27 at 10 weeks). Plasma cortisol was significantly more depressed in the prednisolone group at $40 \%$,versus $84 \%$ in the budesonide group. This comparative trial shows that with the doses used, budesonide is as efficacious as prednisolone in inducing remission in active ileocecal CD. A greater improvement in CDAI was achieved with prednisolone in this time frame, but this did not achieve significance. Budesonide is, however, associated with less steroid side effects and induces significantly less adrenal suppression, as confirmed by others. ${ }^{9-12,14}$

Fluticasone has been tested in enema form without, however, showing a more favourable therapeutic effect than other preparations. ${ }^{15,16}$ More recently, an oral preparation of fluticasone proprionate has been studied in active $\mathrm{UC}^{17,18}$ and compared with prednisolone tablets in the treatment of active CD. ${ }^{19} \mathrm{~A}$ total of 356 patients were entered into the prospective controlled study comparing $20 \mathrm{mg}$ fluticasone with $40 \mathrm{mg}$ prednisolone. The physicians' overall assessment of remission for the fluticasone group was that it was less effective than prednisolone at both two and four weeks, and activity of $\mathrm{CD}$ using the Harvey-Bradshaw Index decreased less in the fluticasone group than the prednisolone group at two weeks, with no difference at four weeks. It was concluded that with the doses used, prednisolone is superior to fluticasone in the therapy of active CD.

Of the new steroids, budesonide is a promising new antiinflammatory agent, and when approved and marketed - and if priced appropriately - should be a key factor in reducing the major, troublesome, long term, systemic side effects of corticosteroids.

\section{REFERENCES}

1. Sawyer AM, et al. Aliment Pharmacol Ther 1991;5:1-14.

2. Jewell DP. Mt Sinai J Med 1990;57:293-6.

3. Brattsand R. Can J Gastroenterol 1990;4:407-14.

4. Edsbacher S, et al. Gastroenterology 1993;104:A695. (Abst)

5. Danielsson A, et al. Scand J Gastroenterol 1992;27:9-12.

6. The Danish Budesonide Study Group. Scand J Gastroenterol 1991;26:1225-30.

7. Lofberg R, et al. Gut 1993;37:T162. (Suppl)

8. Mulder C], Tytgat GN. Aliment Pharmacol Therap 1993;7:125-30.

9. Wolman SL, Greenberg GR. Gastroenterology 1991;100:A263. (Abst)

10. Lofberg R, et al. Gastroenterology 1991;100:A226. (Abst)

11. Roth M, et al. Am J Gastroenterol 1993;8:968-9.

12. Canadian Inflammatory Bowel Disease Study Group. Gastroenterology 1993;104:A675. (Abst)

13. Rutgeerts P, et al. Gastroenterology 1993;104:A772. (Abst)

14. Roth M, et al. Gastroenterology 1992;102:A688. (Abst)

15. De Kaski MC, et al. Gut 1991;32:657-61.

16. Lynn FV, Peppercorn MA. Am J Surg 1992;164:85-9.

17. Angus $\mathrm{P}$, et al, Gut $1992 ; 33: 711-4$.

18. Hawthorne AB, et al. Gut 1993;34:125-8.

19. Wright JP, et al. Gastroenterology 1993;104:A803. (Abst) 


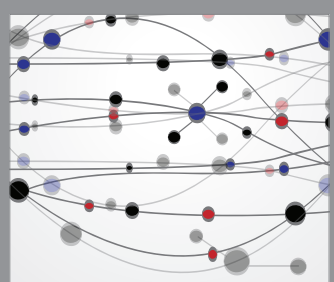

The Scientific World Journal
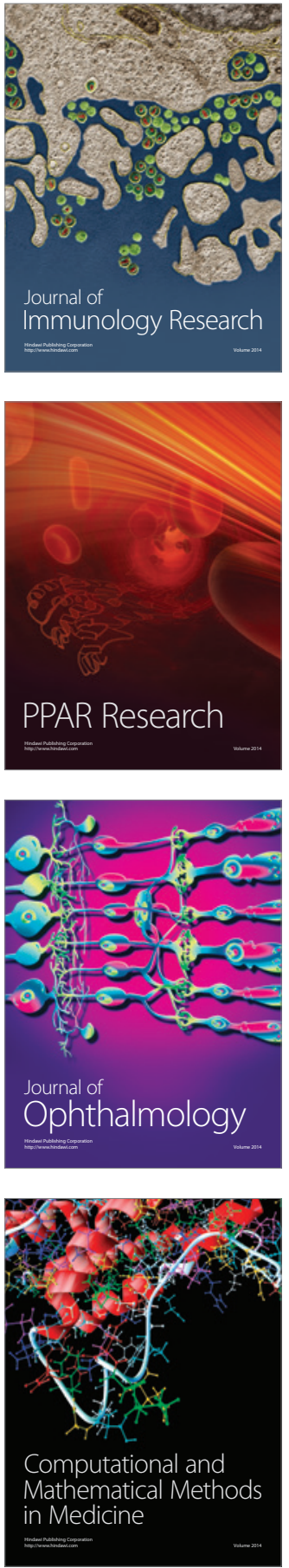

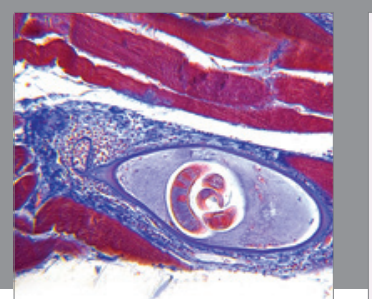

Gastroenterology Research and Practice

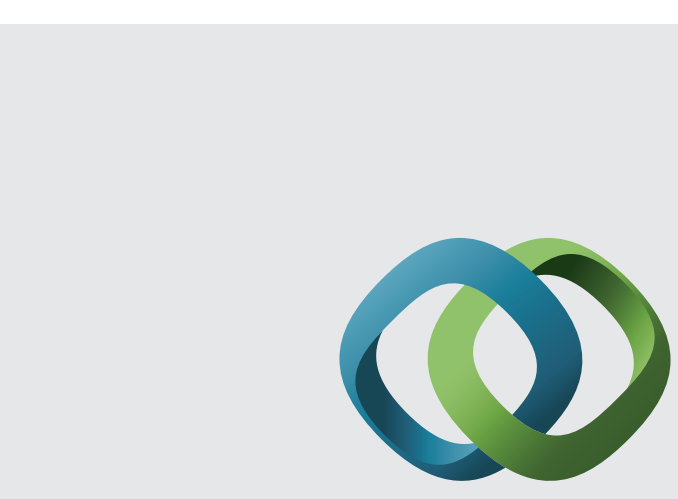

\section{Hindawi}

Submit your manuscripts at

http://www.hindawi.com
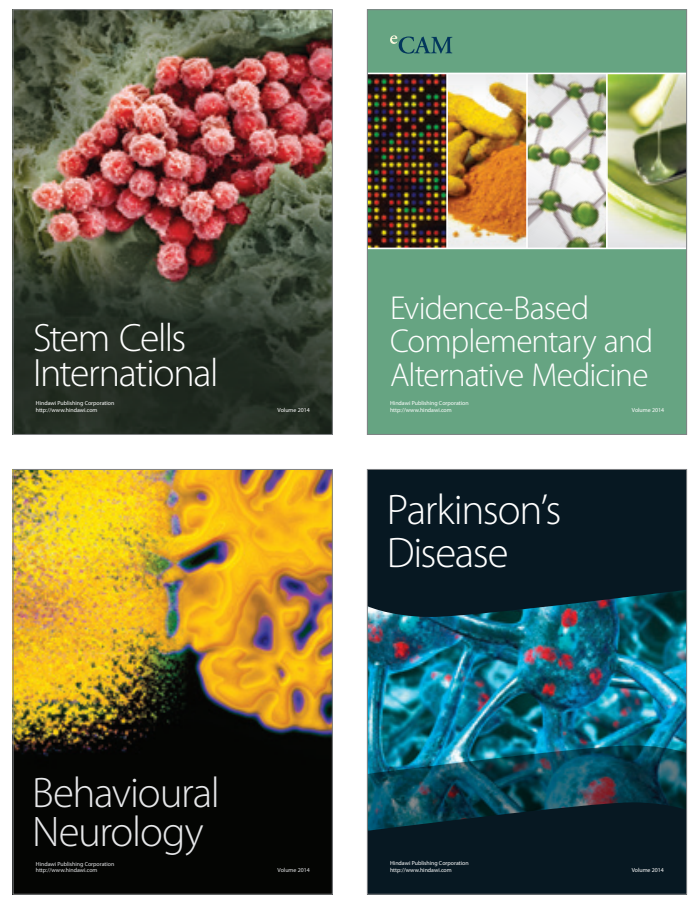
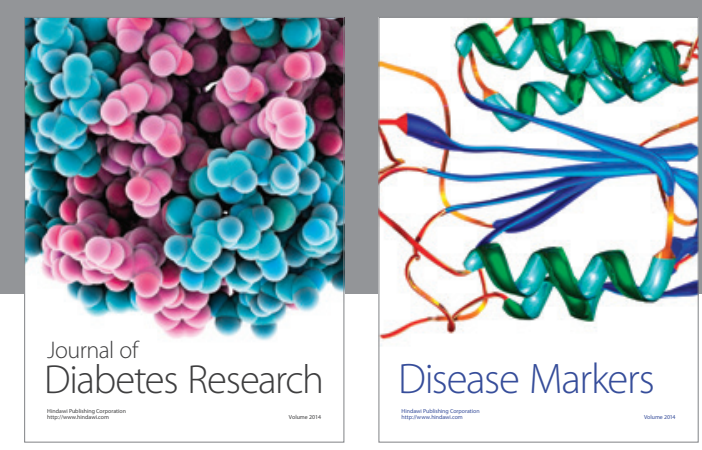

Disease Markers
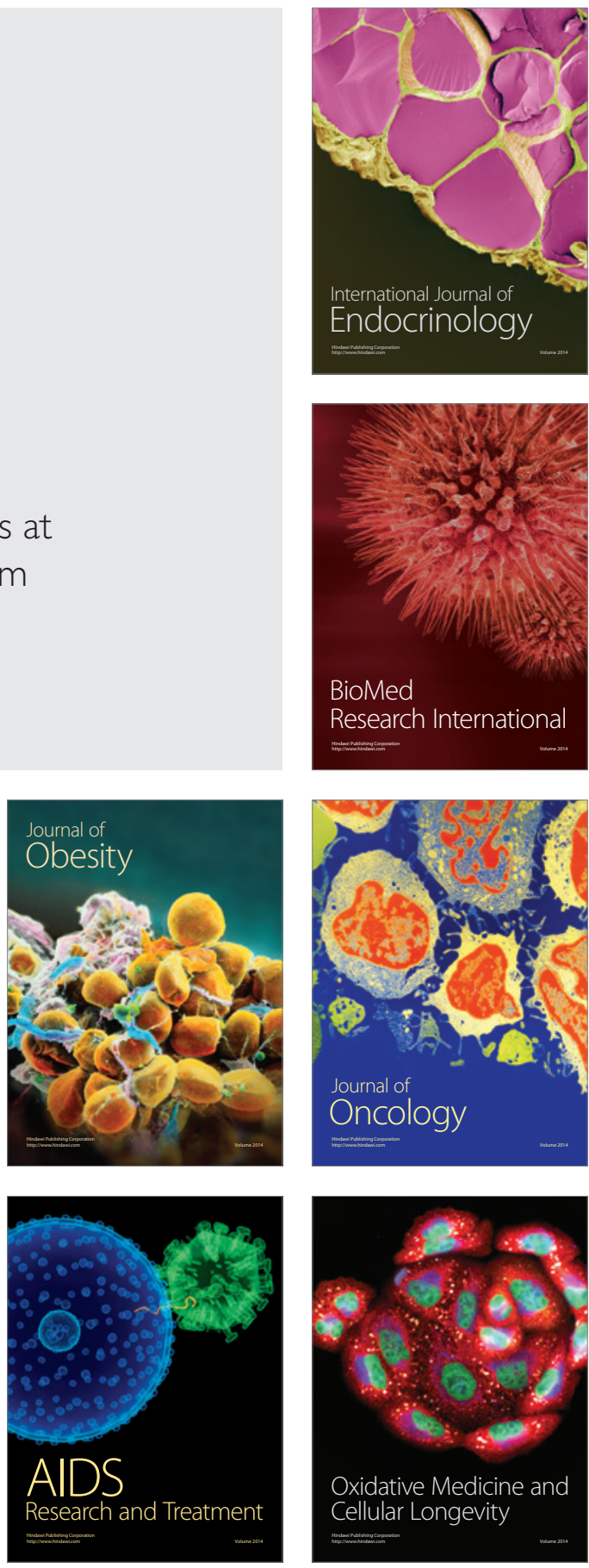